\title{
Pessoas em Situação de Rua pelo olhar da imprensa
}

\author{
Homeless person by the press eye \\ Personas em la Situación de la Calle según el ojo de la prensa
}

Tiago Braga do Espírito Santo

ORCID: https://orcid.org/0000-0002-4313-6894 Universidade do Estado do Rio de Janeiro, Brasil E-mail: tbes81@gmail.com

Letícia Parente Gonçalves

ORCID: https://orcid.org/0000-0003-3522-5894 Escola Nacional de Saúde Pública Sérgio Arouca, Brasil E-mail: leticiiaparente@gmail.com

Natália Estefânia Gaze Teixeira

ORCID: https://orcid.org/0000-0002-9556-7485 Universidade do Estado de Santa Catarina, Brasil E-mail: naatgz@gmail.com

Clarissa Terenzi Seixas

ORCID: https://orcid.org/0000-0002-8182-7776 Universidade do Estado do Rio de Janeiro, Brasil E-mail: ramosporto@openlink.com.br

Fernando Porto

ORCID: https://orcid.org/0000-0002-2880-724X Universidade Federal do Estado do Rio de Janeiro, Brasil E-mail: ramosporto@openlink.com.br

\begin{abstract}
Resumo
Tendo em vista o papel da imprensa, que influencia pautas governamentais e políticas públicas, é importante compreender que, ao publicar conteúdos relacionados à População em Situação de Rua, ela se torna um dos elementos que contribuem na construção do imaginário social. Objetivo: analisar os discursos da imprensa sobre a População em Situação de Rua nos meios de comunicação, à luz dos Padrões de Manipulação da Grande Imprensa de Perseu Abramo. Trata-se de uma pesquisa documental de abordagem qualitativa que utilizou na coleta dos dados a busca na internet pelos termos: moradores de rua, mendigos e População em Situação de Rua, com delimitação temporal de 2014 a 2019. Identificou-se 5 documentos que continham 9 termos, totalizando 29 repetições. O material foi submetido à análise de conteúdo de Bardin, emergindo a categoria "nomenclatura para Pessoas em Situação de Rua e o uso de substâncias psicoativas". A discussão identificou um discurso homogeneizador dos modos de viver na rua, que vincula este grupo ao uso de substâncias psicoativas, de modo estigmatizante, reforçando a exclusão social. Conclui-se pela necessidade de repensar a implicação da imprensa na manutenção do status quo neoliberal, na perpetuação das violências e da invisibilização desse grupo diverso e complexo.

Palavras-chave: População em situação de rua; Vulnerabilidade social; Território sociocultural; Políticas públicas de saúde; Meios de comunicação de massa.
\end{abstract}

\begin{abstract}
In view of the role of the press, which influences government agendas and public policies, it is important to understand its role in the construction of the social imaginary when publishing content related to the Homeless Population. Objective: to analyze the press speeches about the Homeless People in the media in the light of Perseu Abramo's Great Press Manipulation Standards. This is a documentary research with a qualitative approach that used in the data collection the search on the internet for the terms: homeless people, beggars and Population in Street Situation, with time delimitation from 2014 to 2019. 5 documents were identified that contained 9 terms, totaling 29 repetitions. The material was submitted to Bardin's content analysis, emerging the category "nomenclature for Homeless person and the use of psychoactive substances". The discussion identified a homogenizing discourse on the ways of living on the street, which links this group to the use of psychoactive substances, in a stigmatizing way, reinforcing social exclusion. It concludes by the need to rethink the involvement of the media in maintaining the neoliberal status quo, in perpetuating violence and making this diverse and complex group invisible.
\end{abstract}

Keywords: Homeless person; Social vulnerability; Sociocultural territory; Public health policies; Mass media.

\section{Resumen}

Ante el papel de la prensa, que influye en las agendas gubernamentales y las políticas públicas, es importante comprender su papel en la construcción del imaginario social a la hora de publicar contenidos relacionados con la 
Población sin Hogar. Objetivo: analizar los discursos de prensa sobre la población sin hogar en los medios de comunicación a la luz de los grandes estándares de manipulación de la prensa de Perseu Abramo. Se trata de una investigación documental con enfoque cualitativo que utilizó en la recolección de datos la búsqueda en internet de los términos: personas sin hogar, mendigos y Población en Situación de Calle, con delimitación temporal de 2014 a 2019.Se identificaron 5 documentos que contenían 9 términos, totalizando 29 repeticiones. El material fue sometido al análisis de contenido de Bardin, surgiendo la categoría "Nomenclatura de la gente en la calle y el uso de sustancias psicoactivas". La discusión identificó un discurso homogeneizador sobre las formas de vida en la calle, que vincula a este grupo con el uso de sustancias psicoactivas, de manera estigmatizante, reforzando la exclusión social. Concluye con la necesidad de repensar la implicación de los medios de comunicación en el mantenimiento del statu quo neoliberal, en la perpetuación de la violencia y la invisibilidad de este grupo diverso y complejo.

Palabras clave: Personas sin hogar, Vulnerabilidad social, Territorio sociocultural, Políticas de salud, Medios de comunicación de masas.

\section{Introdução}

Apesar das dificuldades obtenção das informações relacionadas a este grupo populacional, é sabido que a População em Situação de Rua (PSR) vem crescendo no Brasil, pelo menos desde 2012. O acesso a esse tipo de informação é dificultado pela não-inclusão da PSR nos censos populacionais realizados, no Brasil, pelo Instituto Brasileiro de Geografia e Estatística (IBGE), tendo em vista a exigência de uma 'base residencial' para inclusão (Natalino, 2020).

Atualmente, o cálculo da PSR é realizado por meio da compilação de análises e modelagens estatística das informações coletadas pelos municípios da Federação, resultando em importantes subnotificações. Em março de 2020, o quantitativo de pessoas em situação de rua nas metrópoles brasileiras era de 92.241, o que aponta para um crescimento de 165\%, quando comparados aos números de setembro de 2012. O mesmo movimento é observado, nos demais municípios do território nacional, com taxa de crescimento de 140\% em período correlato (Natalino, 2020). Os números são ainda mais alarmantes - 146.802 pessoas em situação de rua - quando considerados os indicadores do Cadastro Único para Programas Sociais do Governo Federal (Brasil, 2020).

Esse crescimento pode ser atribuído às dificuldades macroeconômicas, ao desemprego estrutural, à migração, à dependência química e aos conflitos familiares (Natalino, 2020). O Censo específico para a PSR, realizado em 2008, relata que os principais motivos para a ida às ruas foram problemas como alcoolismo e/ou abuso de drogas (35,5\%); desemprego (29,8\%) e desavenças com familiares (29,1\%), sendo a maioria dessas pessoas procedente de municípios do mesmo Estado (Brasil, 2012).

Essa população, na voz corrente, é identificada sob diversas formas: trecheiros, sofredores de rua, moradores de rua e mendigos (Bezerra, et al., 2015). No entanto, esta nomenclatura de cunho pejorativo e estigmatizante, foi revista quando se instituiu o Decreto $n^{\circ}$ 7.053/2009. A partir daí, estabeleceu-se a denominação de População em Situação de Rua para designar um grupo populacional diverso que faz uso de logradouros públicos e outras áreas como espaço de moradia (permanente ou temporária), em situação de extrema pobreza e com vínculos familiares interrompidos. Esta população caracteriza-se, predominantemente, por homens negros, alfabetizados, com idade entre 25 e 44 anos (Brasil, 2009).

Os modos de existir da PSR arranham o verniz do status da normalidade, reafirmando processos de exclusão e preconceito. Isto tem por efeito a produção de desvantagens econômicas e prejuízo no bem estar psíquico, identitário e de pertencimento do grupo (Bezerra, et al., 2015; Paiva, Lira, Justino, Miranda \& Saraiva, 2016). Assim sendo, aponta-se para a necessidade do compromisso do Estado na implementação das políticas públicas (Carmo \& Guizardi, 2018).

A Política Nacional para a População em Situação de Rua (PNPR) vem lutando, desde 1960, em prol de melhores condições de vida e políticas para a conquista de cidadania e autonomia (Brasil, 2010). Porém, a carência por instrumentos quantitativos para investigações desse tipo de população contribui para a sua invisibilidade, apontando para a dificuldade de sua inclusão nas políticas públicas e nos planejamentos governamentais (Schuch, 2015). 
Até aqui, podemos alegar a necessidade de atualização dos dados sobre a PSR, sobretudo no que tange aos riscos à saúde física e mental. Estes riscos se apresentam em virtude de alguns aspectos que atravessam o cotidiano, a saber: isolamento, fragilidade nos laços familiares, uso de drogas, violência física, prática do sexo desprotegido, submissão a trabalhos precários, ausência de renda fixa, dificuldade alimentar, discriminação social e baixo acesso aos serviços de saúde. Dentre os motivos que interditam o acesso à saúde, destacam-se a ausência de documentos de identificação e/ou de residência (Koopmans, at al., 2018).

A problemática acentua-se quando a imprensa, ao mesmo tempo em que direciona os olhares para a situação, distorce a realidade vivida pela PSR. Se o que se espera dos meios de comunicação é que esclareçam a sociedade com dados e argumentos, subsidiando a população com informação para formação de opinião pública, sua atuação tem deixado a desejar quando pseudo-realidades são apresentadas sobre este grupo, inclusive, influenciando as pautas governamentais, bem como as políticas a serem instituídas pelo estado (Koopmans, at al., 2018; Marcos, 1987).

Para este estudo, conceitua-se imprensa como a designação coletiva dos veículos de comunicação que exercem o jornalismo e outras funções da comunicação informativa, desvinculada do entretenimento. Inicialmente restrito ao jornal impresso, o termo imprensa passou a abranger, a partir do século XX, o radiojornal e o telejornal. Atualmente, inclui-se nesse bojo os jornais on-line e toda a gama de comunicação jornalística mediada pela internet, podendo ser também nomeada por meios de comunicação ou mídia (Fonseca, 2011).

Enquanto um dos elementos de construção da realidade nas sociedades contemporâneas, a imprensa é uma área estratégica para mediar a informação no espaço público, intervindo fortemente no cotidiano da população. Por esse poder de influência, o discurso da imprensa auxilia na construção de uma realidade social, através da qual a população se atenta ou negligencia determinados fatos (Abreu, 2002).

Os meios de comunicação, amplamente ocupados por empresas privadas que atuam por interesses lucrativos, ao dar contorno sobre o que é ou não legítimo, pauta a sociedade e, por consequência, o que fica fora deste limite assume um lugar marginal. Destarte, a verdade defendida pela imprensa nem sempre preserva a integralidade e a verdade dos fatos (Fonseca, 2011).

Assim, cabe perguntar-nos: como a veiculação de informações pela imprensa auxilia na configuração dos papéis sociais relacionados à saúde pública, aos profissionais de saúde, às equipes de Atenção Básica e de Consultório na Rua? Como a PSR é pautada pela imprensa?

Assim, considerando-se que a imprensa é formadora de opinião pública e influenciadora das políticas governamentais, e que a ampliação do debate é importante para a visibilização das problemáticas acerca da PSR, esse artigo tem como objetivo analisar os discursos da imprensa sobre PSR nos meios de comunicação.

\section{Metodologia}

Pesquisa documental de abordagem qualitativa, entendida como aquela que se ocupa do caráter subjetivo e relacional da realidade social e que, portanto, deve ser tratada por meio "da história, dos significados, dos motivos, das crenças, dos valores e das atitudes dos atores sociais" (Taquette \& Minayo, 2016).

No intuito de ampliar a coleta de dados na imprensa, utilizou-se recursos da internet por meio do buscador Google, empregando os termos: moradores de rua, mendigos e População em Situação de Rua. Para os critérios de inclusão, definiu-se como universo a publicação de textos jornalísticos publicados nos periódicos tradicionalmente compreendidos como imprensa escrita (jornais), bem como os veículos de imprensa digital (jornais on-line). Como critérios de exclusão, delimitou-se a busca pelos documentos publicados na imprensa acerca da PSR, tendo como delimitação espacial aqueles que se referiam ao entorno 
de uma universidade pública, na zona norte da cidade do Rio de Janeiro, balizados temporalmente pelo período de 2014 a 2019.

Os dados coletados foram submetidos à análise de conteúdo na perspectiva de Bardin (2011), emergindo três categorias. Contudo, por motivos de aprofundamento e limitação das laudas estabelecidas, iremos nos deter à primeira categoria, denominada "nomenclatura para Pessoas em Situação de Rua e o uso de substâncias psicoativas".

Os resultados foram apresentados em tabelas demonstrativas na perspectiva macro - síntese dos registros nos meios de comunicação; e micro - categoria nomenclatura para Pessoas em Situação de Rua e o uso de substâncias psicoativas.

A categoria foi iluminada pelo referencial teórico dos Padrões de Manipulação da Grande Imprensa, de autoria de Perseu Abramo (2016). Este entende que a imprensa se utiliza de quatro padrões para manipular à produção da realidade: 1) ocultação (deliberado silêncio jornalístico sobre determinados aspectos da realidade); 2) fragmentação (a apresentação dos fatos fragmentados, particularizados e desconectados de seus antecedentes e consequências); 3) inversão (reordenação dos fatos a partir da importância atribuída à eles pela órgão de imprensa, destruindo-se a realidade original) e; 4) indução (combinação dos casos anteriores condicionando a população à impossibilidade de ver e compreender a realidade, passando a consumir uma outra realidade artificialmente inventada) (Abramo, 2016).

O estudo foi aprovado pelo Comitê de Ética em Pesquisa (CEP) da Universidade do Estado do Rio de Janeiro (UERJ), sob o CAAE 03768918.9.0000.5282.

\section{Resultados}

Mediante as delimitações e os termos de busca estabelecidos, identificamos 3 meios de comunicação, a saber: jornal O Globo, O Dia e o site G1, totalizando 5 registros.

Tabela 1: Discursos midiáticos nos meios de comunicação sobre a População em Situação de Rua - município do Rio de Janeiro - 2017-2019.

\begin{tabular}{|c|c|c|c|c|}
\hline N. & $\begin{array}{c}\text { Data da } \\
\text { publicação }\end{array}$ & Título da reportagem & Síntese dos conteúdos nos meios de comunicação & $\begin{array}{l}\text { Veículo de } \\
\text { comunicação }\end{array}$ \\
\hline 1 & $04 / 07 / 2017$ & $\begin{array}{l}\text { Comunidade de moradores } \\
\text { de rua se forma perto da } \\
\text { UERJ e do Maracanã }\end{array}$ & $\begin{array}{l}\text { Aborda a formação de um grupo de pessoas em situação de rua que, } \\
\text { segundo os moradores, fazem uso de substâncias psicoativas. } \\
\text { Ressalta a proximidade da comunidade à UERJ e ao estádio } \\
\text { Maracanã (um dos principais pontos turísticos da cidade), enfatizando } \\
\text { a importância turística do local. }\end{array}$ & G1 \\
\hline 2 & $23 / 01 / 2018$ & $\begin{array}{l}\text { Prefeitura do Rio fará novo } \\
\text { levantamento de moradores } \\
\text { de rua após número triplicar }\end{array}$ & $\begin{array}{l}\text { Informa sobre o aumento de } 156 \% \text { da PSR (de } 2013 \text { a 2018) e sobre } \\
\text { planejamento da Secretaria Municipal de Assistência Social e } \\
\text { Direitos Humanos (SMASDH) de realizar um mapeamento dos } \\
\text { "moradores de rua", qualificando seus dados demográficos, de acesso } \\
\text { à renda e à rede de saúde dessa população. Relata que, a partir de } \\
\text { março de } 2019 \text {, a Secretaria oferecerá cursos profissionalizantes em } \\
\text { dois abrigos na região central do município }\end{array}$ & G1 \\
\hline 3 & $21 / 05 / 2018$ & $\begin{array}{l}\text { Moradores estão assustados } \\
\text { com crescimento de } \\
\text { cracolândia no Maracanã }\end{array}$ & $\begin{array}{l}\text { Enfatiza o medo dos moradores da região com a expansão da } \\
\text { "cracolândia". Destaca os assaltos a pedestres. A SMASDH relata as } \\
\text { ações que encaminham as pessoas para abrigos, mas tem sua ação } \\
\text { cerceada por respeitar a lei e a decisão dos cidadãos. }\end{array}$ & O Dia \\
\hline 4 & $08 / 06 / 2018$ & Quatro anos após a Copa do & Traz relato de moradores sobre o abandono do local após o evento da & G1 \\
\hline
\end{tabular}


Research, Society and Development, v. 10, n. 4, e38010414196, 2021

(CC BY 4.0) | ISSN 2525-3409 | DOI: http://dx.doi.org/10.33448/rsd-v10i4.14196

Mundo, região do maracanã

sofre com irregularidades,

usuários de drogas e

aumento da violência

5
Copa do Mundo (2014). Destaca o aumento de 220\% dos roubos na região. Apresenta como problemas: a existência de "usuários de drogas", o crescimento de lava-jatos irregulares, o aumento da criminalidade e a ocupação do Museu do Índio. Destaca a importância do Maracanã e relaciona o aumento da criminalidade ao encerramento do maior esquema de segurança da história na Copa do Mundo. Relata que os moradores atribuem a criminalidade à "cracolândia" e apresenta o relato de uma enfermeira que trabalha na região, que destaca a sensação de vulnerabilidade em relação ao espaço e à "movimentação de pessoas suspeitas". A SMASDH informa sobre "projetos de recuperação dos viciados", ressaltando que agem conforme a vontade do cidadão e que o acolhimento compulsório é proibido.

Destaca a presença de móveis e equipamentos eletrônicos no local

O Globo ocupado pelas PSR, afirmando que o local é a extensão 'Cracolândia da UERJ'. Afirma seu crescimento, apesar das intervenções do poder público. Informa que os usuários de drogas interditam o contato, tendo ateado fogo em móveis e arremessado pedras na Guarda Municipal. Afirma que o espaço é ocupado por "dezenas de pessoas que consumiam drogas em meio a muita sujeira". Alega que a SMASDH atendeu 40 "dependentes químicos" na primeira quinzena de 2018, ofertando acolhimento e atendimento em saúde, mas foram impedidos pela "profunda relação do grupo com o uso de crack". Destaca os constantes assaltos a comerciantes da região e estudantes da UERJ.

Fonte: Autores.

Nesta tabela é importante notar como a imprensa apresenta suas narrativas acerca da Pessoa Em Situação de Rua. Ao aplicarmos o processo da análise de conteúdo, a categoria "nomenclatura para Pessoas em Situação de Rua e o uso de substâncias psicoativas" emergiu. Esta se destina a nomenclatura aplicada pela imprensa à PSR, vinculando-as ao uso de substâncias, com repetições de termos e expressões que marcaram o texto. Logo, elas foram identificadas e quantificadas com apresentação na Tabela 2. 
Tabela 2: Frequência das nomenclaturas atrelada às pessoas em situação de rua vinculadas ao uso de substâncias psicoativas por documento encontrados na imprensa - município do Rio de Janeiro - 2020.

\begin{tabular}{|c|c|c|c|c|c|c|}
\hline \multicolumn{7}{|c|}{ Frequência por documento } \\
\hline $\begin{array}{c}\text { Palavras ou } \\
\text { expressões }\end{array}$ & $\begin{array}{c}\text { Comunidade de } \\
\text { moradores de } \\
\text { rua se forma } \\
\text { perto da UERJ e } \\
\text { do Maracanã } \\
\text { (G1) }\end{array}$ & $\begin{array}{l}\text { Prefeitura do Rio } \\
\text { fará novo } \\
\text { levantamento de } \\
\text { moradores de rua } \\
\text { após número } \\
\text { triplicar (G1) }\end{array}$ & $\begin{array}{l}\text { Moradores estão } \\
\text { assustados com } \\
\text { crescimento de } \\
\text { Cracolândia no } \\
\text { Maracanã (O } \\
\text { Dia) }\end{array}$ & $\begin{array}{c}\text { Quatro anos após a } \\
\text { Copa do Mundo, região } \\
\text { do maracanã sofre com } \\
\text { irregularidades, } \\
\text { usuários de drogas e } \\
\text { aumento da violência } \\
\text { (G1) }\end{array}$ & $\begin{array}{c}\text { Cracolândia } \\
\text { cresce e toma } \\
\text { canteiros e } \\
\text { calçadas do } \\
\text { Maracanã (O } \\
\text { Globo) }\end{array}$ & Total \\
\hline Cracolândia & 0 & 0 & 2 & 4 & 6 & 12 \\
\hline $\begin{array}{l}\text { Usuário de } \\
\text { drogas }\end{array}$ & 0 & 0 & 1 & 4 & 1 & 6 \\
\hline $\begin{array}{c}\text { Dependentes } \\
\text { Químicos }\end{array}$ & 0 & 0 & 0 & 0 & 4 & 4 \\
\hline $\begin{array}{c}\text { Usam } \\
\text { entorpecentes }\end{array}$ & 2 & 0 & 0 & 0 & 0 & 2 \\
\hline Usuários & 0 & 0 & 0 & 1 & 0 & 1 \\
\hline $\begin{array}{c}\text { Usuário de } \\
\text { álcool e drogas }\end{array}$ & 0 & 0 & 1 & 1 & 0 & 2 \\
\hline Viciados & 0 & 0 & 0 & 1 & 0 & 1 \\
\hline $\begin{array}{c}\text { "Pessoas que } \\
\text { usam drogas em } \\
\text { meio a muita } \\
\text { sujeira" }\end{array}$ & 0 & 0 & 0 & 0 & 1 & 1 \\
\hline $\begin{array}{l}\text { “profunda } \\
\text { relação do } \\
\text { grupo com o } \\
\text { uso de Crack." }\end{array}$ & 0 & 0 & 0 & 0 & 1 & 1 \\
\hline
\end{tabular}

Fonte: Autores.

Nesta tabela é importante atentar para a quantidade de expressões utilizadas pela imprensa ao se referir à Pessoa em Situação de RUA, bem como a presença de repetições nos textos. Em síntese, 9 expressões foram atribuídas à PSR na categoria de pessoas em uso de substâncias psicoativas, tendo como frequência totalizada um quantitativo de 29 palavras e expressões, o que é apresentado na Tabela 3. 
Tabela 3: Frequências das expressões aplicadas pelos operadores da imprensa.

Palavras ou trechos documentos

Cracolândia

Usuários de drogas

Dependentes químicos

Usam entorpecentes

Usuários

Usuário de álcool e drogas

Viciados

Pessoas que usam drogas em meio a muita sujeira

"Profunda relação do grupo com o uso de Crack."

TOTAL
$\mathrm{N}^{\circ}$ de repetições nos documentos

12 vezes

6 vezes

4 vezes

2 vezes

$1 \mathrm{vez}$

1 vez

$1 \mathrm{vez}$

$1 \mathrm{vez}$

$1 \mathrm{vez}$

29 vezes

Fonte: Autores.

Nesta tabela evidencia-se as repetições das palavras ou trechos utilizados pela imprensa. O termo que apresentou maior frequência foi "Cracolândia" e aqueles menos presentes foram "Usuários, Usuário de álcool e drogas, Viciados, Pessoas que usam drogas em meio a muita sujeira" e "profunda relação do grupo com o uso de Crack".

Nos termos e expressões "Usuários, Usuário de álcool e drogas, Viciados, Pessoas que usam drogas em meio a muita sujeira" e "profunda relação do grupo com o uso de Crack" atribuídos à PSR, podemos identificar o uso de usuário/viciado como grupo articulado ao álcool, drogas (Crack) em ambiente de sujeira.

Isso aponta para a construção no imaginário do leitor sobre o contexto da PSR. Trata-se de uma construção social, que demarca os valores, como se fossem generalizantes e aceitos como verdade, inclusive potencializados pelas expressões "Usuários de drogas", "Dependentes químicos" e "Usam entorpecentes” com frequências medianas.

Em síntese, nos meios de comunicação essa população é apresentada como pessoas que habitam lugares sujos e fazem uso e comercialização de drogas e álcool - uma cracolândia - de forma generalizada, sendo nesta perspectiva que iremos discutir os resultados desta categoria.

\section{Discussão}

A função da imprensa é a divulgação de fatos sociais, econômicos, culturais e políticos pertinentes e de interesse da população, por meio da caracterização pela história, de forma abrangente ou generalista. Esta desempenha, portanto, função na vida cotidiana daqueles que a consomem, sendo um dos meios de comunicação que mais instrui o coletivo (Oliveira, 2010).

Por serem meios de disseminação dos fatos, os órgãos da imprensa devem ter o compromisso com a imparcialidade, ou seja, manterem-se neutros de interesses. Por outro lado, eles encontram-se inseridos em determinados contextos e seguem determinada linha editorial a ser adotada pelas pautas e conteúdos publicados (Abramo, 2016).

O editor é o responsável por definir a linha editorial. Esta trata-se de alinhamento das disposições, por meio de suas convicções e interesses econômicos, em concordância com a dos empresários que sustentam os meios de comunicação. Desta forma, no Brasil, a imprensa dificilmente se encontra despida de interesses, pois opera como porta-voz de determinados grupos sociais no país, trabalhando em manipulações para produção de sentido (Abramo, 2016; Paixão, 2018). 
Portanto, é por meio desse contexto, que os discursos da imprensa, ao serem compreendidos como produtores de sentidos e de verdades, subjetivam-se no cotidiano das pessoas. É esse o conteúdo que concede visibilidade a certas realidades enquanto invisibiliza outras, tornando-se elemento em prol do governo das vidas. O que se configura, portanto, são regimes de verdade produzidos no interior das sociedades, que planificam condutas humanas e antecipam singularidades, submetendo os indivíduos às normativas do poder, adestrando os comportamentos e controlando os corpos (Foucault, 1996).

Cada veiculo da imprensa possui interesses direcionados que produzem sentidos à população. Isto implica em um direcionamento no olhar dos leitores para determinados campos em detrimento de outros. Ocorre, assim, a manipulação, distorcendo a realidade e recriando-a, com uma visão parcial ou até mesmo antagônica dos fatos (Abramo, 2016).

Na categoria "nomenclatura para Pessoas em Situação de Rua e o uso de substâncias psicoativas" percebe-se que há 9 termos relacionados ao uso de drogas, o que conduz à compreensão reduzida dos fatos por parte do leitor.

A "cracolândia", citada 12 vezes, aparece vinculada à aglomeração de "usuários de drogas", próximo à universidade pública da zona norte da cidade do Rio de Janeiro, além dos lava-jatos de automóveis irregulares que se instalaram nos locais.

Outro dado relevante presente nos documentos encontrados é a ocupação existente no Museu do Índio, que é atrelada ao medo que os moradores do local têm com a possibilidade de favelização do território. Este fato carece de elucidação nos textos encontrados. Entretanto, por si só, produz sentido sugestivo que o movimento é realizado pela PSR ou por usuários de substâncias.

Na Pesquisa Nacional sobre a População em Situação de Rua, de 2008, o uso de substâncias aparece como o principal motivo para a ida para as ruas. No entanto, este documento também apresenta como fatores o desemprego e as desavenças familiares (Brasil, 2012). Estes últimos não são abordados pelo discurso da imprensa, destacando-se, exclusivamente, o consumo de drogas.

Essa argumentação coaduna com pesquisa sobre o uso de álcool pela PSR em Belo Horizonte. Nela, os autores evidenciaram a prevalência de $17,55 \%$ de abstêmios, $21,22 \%$ com uso em baixo risco, $20 \%$ em uso de risco, 9,80\% em uso nocivo e 31,43\% como prováveis dependentes. Nota-se que 61,22\% dos participantes apresentaram uso de risco de álcool (Botti, et al., 2010). Esta realidade é evidenciada, também, por outro estudo no âmbito internacional, na Inglaterra, que aponta para a importante prevalência do alcoolismo na PSR (Scott, 1993; Shanks, 1983).

Em contrapartida, outro estudo aponta que o reconhecimento da existência do fenômeno do uso de substâncias associadas a PSR demanda cuidadosa reflexão e qualificação de quem são as pessoas envolvidas. Nestas situações, a imprensa, ao reduzirem as circunstâncias à estigmatizações que podem estar equivocadas, atua como elemento constitutivo da formação de opinião pública capturada por um viés da moralidade (Torossian, Torres \& Kveller, 2017).

O compartilhamento por um grupo populacional das mesmas condições nas ruas não significa o estabelecimento de um padrão estereotipado e estigmatizado. Cabe, portanto, a qualificar a análise para não cristalizar ou, como se diz na voz corrente, rotular que todos em situação de rua são drogados. Esta heterogeneidade não é visualizada pelo senso comum e pelos serviços de saúde, produzindo juízo moral, exclusão social e problemas para a saúde física e mental da PSR (Campos, et al., 2019).

Contudo, a díspar do que vem sendo produzido academicamente, é notável a homogeneização do discurso apresentado pelos documentos encontrados, que publicizam a relação entre a PSR e o uso de drogas. Agravando a situação, os documentos da imprensa destacam a importância do território, apontando seu valor turístico e demonstrando uma preocupação com o incômodo produzido pela PSR e a consequente desvalorização do espaço.

Assim sendo, ao dar luz a certos aspectos da realidade, percebe-se a utilização da Inversão como padrão de manipulação (Abramo, 2016). Nesta, após a fragmentação e a descontextualização dos fatos, opera-se sua reordenação a partir da importância atribuída pela imprensa, destruindo-se a realidade original. Em outras palavras: o que a imprensa faz é atribuir 
o status de usuário de drogas à PSR e, posteriormente, destacar a importância da desvalorização territorial, atribuindo à presença deles o principal motivo.

Prioriza-se, assim, a capitalização do espaço em detrimento da pessoa. Destarte, o que se produz são regimes de verdades que induzem o leitor a uma realidade influenciada pela importância que a imprensa dá a certos aspectos de uma realidade artificialmente inventada.

Ainda, sobre o uso das substâncias psicoativas, os resultados apontam que as intervenções do Estado se centraram em "ações de acolhimento". Estas são realizadas pela Secretaria Municipal de Assistência Social e Direitos Humanos (SMASDH), quando encaminham as "pessoas em situação de rua" para um Hotel Solidário.

Prosseguindo com um discurso que vincula a PSR ao uso de substâncias, os documentos informam que, por conta da "profunda relação com o uso do crack", 40 "dependentes químicos" da região foram atendidos na primeira quinzena do ano de 2019, com oferta de "ações de recolhimento" promovidas pela SMASDH. Os discursos midiáticos destacam a impossibilidade da realização da internação compulsória, tendo em vista sua proibição legal (O Globo, 2019).

A atuação da SMASDH frente a esse grupo populacional é destacada por um estudo, no âmbito da política de assistência social, tendo demonstrado a desarticulação entre os setores, a descontinuidade dos programas voltados à PSR e o destaque das políticas focalizadoras que perpetuam o exercício das punições e das condutas de isolamento (Paiva, Lira, Justino, Miranda \& Saraiva, 2016).

As narrativas da imprensa presentes nos documentos encontrados limitam a interpretação do leitor ao não citar a existência ou possibilidade de atuação do Consultório na Rua (CnaR). Este é um dispositivo instituído pela Política Nacional de Atenção Básica, na Portaria $\mathrm{n}^{\circ}$ 2.488, de 21 de outubro de 2011, para o atendimento específico à PSR. Os CnaR se caracterizam por um conjunto de ações de saúde - individuais e coletivas - que abrangem promoção e proteção da saúde, prevenção de agravos, diagnóstico, tratamento, reabilitação, redução de danos e manutenção da saúde. Seus objetivos são o desenvolvimento de atenção integral, que impacte na situação de saúde, na autonomia das pessoas e nos determinantes e condicionantes de saúde das coletividades (Brasil, 2011).

A atenção à saúde da PSR é responsabilidade dos profissionais de saúde no Sistema Único de Saúde (SUS), não restringindo-se, exclusivamente, a uma equipe de Consultório na Rua (eCR). Em municípios ou áreas em que não há eCR, a atenção deve ser prestada pelas demais modalidades de equipes da Atenção Básica, bem como dos Núcleos de Apoio à Saúde da Família (NASF), dos Centros de Atenção Psicossocial (CAPS), dos serviços de Urgência e Emergência e de outros pontos de atenção do território, de acordo com as necessidades da pessoa (Brasil, 2011).

Desta forma, ao relatar apenas as ações e posicionamentos da SMASDH, descartando todo o leque de ações desenvolvidas pelos serviços da Atenção Básica, CnaR e dos dispositivos psicossociais de caráter aberto, a imprensa utiliza a Ocultação como Padrão de Manipulação, recortando o fato e excluindo deliberadamente aspectos da realidade (Abramo, 2016).

A utilização da Ocultação invisibiliza a competência e a potência dos dispositivos do campo da saúde no âmbito do SUS. Ao destacarem a impossibilidade da internação compulsória, os documentos localizados optaram pelo relato do que era impedido pela normativa jurídica. Assim, a realidade produzida pela imprensa direciona o leitor ao entendimento de que a Secretaria Municipal de Assistência Social e Direitos Humanos tem sua ação interditada pelos limites da lei.

Nesse sentido, como apontado por uma Revisão Integrativa de Literatura acerca da PSR, o que se percebe é a materialização da lógica capitalista do Estado que se efetiva em ações de fiscalização das áreas públicas, dificultando sua existência e intensificando sua vulnerabilização. Estas atuações, enquanto políticas de governo, ressignificam a compreensão do "Estado social" na direção do "Estado penal" (Paiva, et al., 2016).

Cabe ressaltar os profissionais que atuam nos serviços públicos de saúde, de um modo geral, desconhecem as particularidades e homogeneízam a população por meio de seus estigmas e rótulos, não estando aptos para a produção de 
cuidado direcionado a esse grupo populacional (Rios, et al., 2020). Este fato faz persistir os problemas de acesso aos serviços, bem como a efetivação de ações higienistas e medicalizantes, pautadas em um paradigma uni causal voltado às doenças (Paiva, et al., 2016).

A imprensa é um elemento de influencia nas agendas e políticas públicas. Ao apartar as possibilidades de ação pelo campo da saúde, contribui para a cristalização de uma abordagem relacionada à Assistência Social e ao campo jurídico. Ao serem afastados do direito à saúde pelos discursos da imprensa, a realidade artificialmente inventada contribui para a produção e reafirmação do entendimento social da PSR a partir de regulações limitadoras que efetivam a maior governabilidade dos corpos.

\section{Considerações Finais}

Apesar do quantitativo de documentos utilizados ser pouco representativo e não poder concluir afirmativas acerca de tudo o que foi publicado pela imprensa, o material encontrado apresenta importantes elementos que dizem respeito à produção artificial da realidade. Como limites do estudo, apontamos lacunas ao não apresentarmos as 2 categorias oriundas da investigação, mas ratificamos os nossos argumentos, aprofundando a análise proposta. Destaca-se, contudo, que existem mais elementos que contribuem para o entendimento da significação da PSR que serão discutidos em estudos futuros.

A análise demonstrou que a imprensa, ao pautar a PSR, a vinculam sistematicamente a ambientes com baixas condições de higiene e uso de substâncias psicoativas, aos quais atribuem o nome de Cracolândia. Contudo, a discussão evidenciou um outro lado sobre a PSR que vem sendo sistematicamente omitido, talvez, para potencializar o consumo do leitor. Este movimento, por consequência, acaba por contribuir para a cristalização de certas condições sociais para não arranhar o verniz do que é moralmente aceito.

O discurso da imprensa evidenciou a relação tácita entre a PSR e o uso de substâncias psicoativas. Homogeneíza-se assim um grupo populacional complexo a partir de características que sedimentam a exclusão, a imobilidade social, a humilhação e a violência. Poderíamos afirmar que o fenômeno PSR relaciona-se à problemática inerente à sociabilidade neoliberal. Nesse bojo, a construção identitária estigmatizante alinha-se ao regime de verdade que favorece a perpetuação das categorias socialmente aceitas a partir dos critérios de normalidade da atual conjuntura. A narrativa da imprensa, afinada a este regime de verdade, coisifica identidades e influencia o entendimento social.

Sabe-se que a compreensão das particularidades da PSR não é suficiente para dar conta do problema da exclusão social. Contudo, a produção do conhecimento acerca dos regimes de verdade que agenciam o controle dos corpos e seus modos de existir, aumenta a sua visibilidade e gera discussões acerca da necessidade de construção e efetivação das políticas públicas para reduzir as iniquidades sociais. Acredita-se neste caminho formativo como possibilidade para a interrupção do ciclo de violência física e simbólica vivenciada cotidianamente pela PSR.

Desta forma, a análise apresentada contribui para a reflexão acerca da necessidade de implementação de políticas direcionadas ao acesso desse grupo populacional à saúde e à assistência social como condição para a redução dos preconceitos, vulnerabilização e das violências que lhes são cotidianamente impostas na sociabilidade capitalista. Para tanto, sugere-se o desenvolvimento de estudos e propostas que respondam às demandas da PSR por trabalho, moradia e acesso aos serviços públicos, elementos fundamentais para a reconstrução da cidadania e da dignidade.

Aponta-se também para a necessidade de produção de dados e de novos estudos que deem conta da heterogeneidade da PSR, visibilizando a complexidade das relações sociais estabelecidas e as múltiplas possibilidades de ocupação do mundo e das maneiras de existir. São os dados da realidade objetiva na qual estão inseridos que proporcionarão o desenvolvimento de políticas públicas atentas ao desenvolvimento de outras formas de sociabilidade, em contraposição à concepção depreciativa 
que nossa sociedade oferta à Pessoa em Situação de Rua. Novos estudos também serão desenvolvidos a partir das outras categorias que emergiram da analise do conteúdo dos documentos encontrados.

\section{Referências}

Abramo, P. (2016). Padrões de Manipulação na Grande Imprensa. 2a Edição. São Paulo: Fundação Perseu Abramo. http://biblioteca.clacso.edu.ar/Brasil/fpa/20170912055155/pdf_1475.pdf.

Abreu, A. A. (2002). A Modernização da Imprensa (1970-2000). Jorge Zahar.

Bardin, L. (2011). Análise de conteúdo. Edições 70.

Bezerra, W. C., Firmino, G. C. S., Javarrotti, E. S., Melo, J. V. M., Calheiros, P. F. F. \& Silva, R. G. L. B. (2015). O cotidiano de pessoas em situação de rua: rupturas, sociabilidades, desejos e possibilidades de intervenção da Terapia Ocupacional. Cad. Ter. Ocup 23(2). http://doi.editoracubo.com.br/10.4322/01044931.ctoAO0541.

Botti, N. C. L., Castro, C. G., Silva, A. K., Silva, M. F., Oliveira, L. C., Castro, A. C. H. O. A. \& Fonseca, L. L. K. (2010). Padrão de uso de álcool entre homens adultos em situação de rua de Belo Horizonte. Rev. Eletrônica Saúde Mental Álcool Drog. 6, 20. http://pepsic.bvsalud.org/pdf/smad/v6nspe/10.pdf.

Brasil. (2009). Decreto $n^{\circ}$ 7.053, de 23 de dezembro de 2009. Institui a Política Nacional para a População em Situação de Rua e seu Comitê Intersetorial de Acompanhamento e Monitoramento, e dá outras providências [periódico na Internet]. Diário Oficial da União 2009. http://www.planalto.gov.br/ccivil_03/_Ato2007-2010/2009/Decreto/D7053.htm.

Brasil. (2020). Nota Técnica N. ${ }^{\circ}$ 5/2020/CGRIS/DEPEDH/SNPG/MMFDH, de 3 de abril de 2020. Orientações Gerais sobre Atendimento e Acolhimento Emergencial à população em situação de rua no contexto da pandemia do Covid-19. Brasília, DF. https://www.gov.br/mdh/pt- br/assuntos/noticias/20202/abril/ministerio-da-orientacoes-para-acolhimento-da-populacao-emsituacao-de-rua-durante-pandemia/SEI_MDHNotaTcnicaOrientaesPopRuaCovid19.pdf

Brasil. (2011). Portaria $\mathrm{n}^{\circ}$ 2488, de 21 de outubro de 2011. Aprova a Política Nacional de Atenção Básica, estabelecendo a revisão de diretrizes e normas para a organização da Atenção Básica, para a Estratégia Saúde da Família (ESF) e o Programa de Agentes Comunitários de Saúde (PACS). Diário Oficial da União [portaria na Internet]. 2011. http://bvsms.saude.gov.br/bvs/saudelegis/gm/2011/prt2488_21_10_2011.html.

Brasil. (2012). Manual sobre o cuidado à saúde junto à População em Situação de Rua. http://189.28.128.100/dab/docs/publicacoes/geral/manual_cuidado_populalcao_rua.pdf.

Brasil. (2010). Movimento Nacional da População de Rua. Cartilha de Formação do Movimento Nacional da População de Rua. 2010. http://www.direito.mppr.mp.br/arquivos/File/MNPR_Cartilha_Direitos_Conhecer_para_lutar.pdf.

Campos, L. C. M., Oliveira, J. F., Porcino, C., Reale, M. J. O. U., Santos, M. V. S. \& Jesus, M. E. F. (2019). Representações Sociais De Pessoas Em Situação De Rua Sobre Morador De Rua Que Usa Drogas. Rev. Baiana Enferm. http://www.revenf.bvs.br/pdf/rbaen/v33/1984-0446-rbaen-33-e26778.pdf.

Carmo, M. E. \& Guizardi, F. L. (2018). O conceito de vulnerabilidade e seus sentidos para as políticas públicas de saúde e assistência social. Cad. Saúde Pública 34(3). https://www.scielo.br/pdf/csp/v34n3/1678-4464-csp-34-03-e00101417.pdf.

Fonseca, F. (2011). Mídia, poder e democracia: teoria e práxis dos meios de comunicação. Revista Brasileira de Ciência Política, no 6. Brasília. http://www.scielo.br/pdf/rbcpol/n6/n6a03.pdf.

Foucault, M (1996). A ordem do discurso. (3a ed.), Edições Loyola https://moodle.ufsc.br/pluginfile.php/1867820/mod_resource/conten t/1/FOUCAULT\% 2C\%2 0Michel\%20-\%20A\%20ordem\%20do\%20discurso.pdf.

Koopmans, F. F., Daher, D. V., Acioli, S., Sabóia, V. M., Ribeiro, C. R. B. \& Silva, C. S. S. L. (2018). Living on the streets: an integrative review about the care for homeless people. Rev. Bras. Enferm; 72(1). https://www.scielo.br/pdf/reben/v72n1/0034-7167-reben-72-01-0211.pdf.

Marcos, L. R. Media power and public mental health policy. (1989). Am J. Psychiatry; 146(9). https://pubmed.ncbi.nlm.nih.gov/2764177/.

Natalino, M. A. C. Nota Técnica n ${ }^{\circ} 73:$ Estimativa da população e situação de rua no Brasil (setembro de 2012 a março de 2020 ). (2020). Instituto de Pesquisa Econômica e Aplicada. https://pesquisa.bvsalud.org/portal/resource/pt/biblio-1100681.

O Globo [reportagem na Internet]. (2019); Cracolândia da UERJ cresce e toma canteiros e calçadas do Maracanã. https://oglobo.globo.com/rio/cracolandiada-uerj-cresce-toma-canteiros-calcadas-do-maracana-23425696.

Oliveira, E. T. (2010). A linguagem tendenciosa na mídia impressa: um estudo de caso sobre a indução do leitor. Identidade Científica 1(2). http://www.unoeste.br/facopp/revista_facopp/IC2/IC25.pdf.

Paiva, I. K. S., Lira, C. D. G., Justino, J. M. R., Miranda, M. G. O. \& Saraiva, A. K. M. (2016). Direito à saúde da população em situação de rua: reflexões sobre a problemática. Cien Saude Colet 21(8). http://www.scielo.br/pdf/csc/v21n8/1413-8123-csc-21-08-2595.pdf.

Paixão, P. (2018). Linha editorial no jornalismo brasileiro: conceito, gênese e contradições entre a teoria e a prática. Revista Alterjor; 01(17). http://www.revistas.usp.br/alterjor/article/view/137224/137486.

Rios, A. G, Seixas, C. T, Cruz, K. T, Junior, H. S, Merhy, E. E \& Santiago, S. M. (2020) A produção do comum como estratégia de cuidado para usuários complexos: Uma cartografia com mulheres em situação de rua. Cien Saude Colet. http://www.cienciaesaudecoletiva.com.br/artigos/a-producao-do-comumcomo-estrategia-de-cuidado-para-usuarios-complexos-uma-cartografia-com-mulheres-em-situacao-de-rua/17665?id=17665. 
Research, Society and Development, v. 10, n. 4, e38010414196, 2021

(CC BY 4.0) | ISSN 2525-3409 | DOI: http://dx.doi.org/10.33448/rsd-v10i4.14196

Schuch, P. (2015). A legibilidade como gestão e inscrição política de populações: notas etnográficas sobre a política para pessoas em situação de rua no Brasil. In: Fonseca, C.; Machado, H., Ciência, identificação e tecnologias de governo. Editora da UFRGS/Cegov,

Scott, J. (1993). Homelessness and mental illness. Br J Psychiatry [serial on the Internet]; 162. https://www.cambridge.org/core/journals/the-british-journal-ofpsychiatry/article/abs/homelessness-and-mental-illness/96004FD276BC2033797FDCE694D8D3DB\#access-block.

Shanks, N. J. Medical provision for the homeless in Manchester (1983). J Royal College Gen Pract; 33: https://www.ncbi.nlm.nih.gov/pmc/art icles/PMC1972614/pdf/jroyalcgprac00073-0042.pdf.

Taquette, S. R. \& Minayo, M. C. (2016). Análise de estudos qualitativos conduzido por médicos publicados em periódicos científicos brasileiros entre 2004 e 2013. Physis Revista de Saúde Coletiva; 26(2). https://www.scielo.br/pdf/physis/v26n2/0103-7331-physis-26-02-00417.pdf.

Torossian, S. D., Torres, S. \& Kveller, D. B. (2017). Descriminalização do cuidado: políticas, cenários e experiências em redução de danos. Porto Alegre: Rede Multicêntrica. https://lume.ufrgs.br/bitstream/handle/10183/159458/001023841.pdf?sequence=1\&isAllowed=y . 